Purdue University

Purdue e-Pubs

2019

\title{
The Petal Effect of Parahydrophobic Surfaces offers Low Receding Contact Angles that Promote Effective Boiling
}

T.P. Allred

Purdue University

J.A. Weibel

Purdue University, jaweibel@purdue.edu

S V. Garimella

Purdue University, sureshg@purdue.edu

Follow this and additional works at: https://docs.lib.purdue.edu/coolingpubs

Allred, T. P.; Weibel, J. A.; and Garimella, S V., "The Petal Effect of Parahydrophobic Surfaces offers Low Receding Contact Angles that Promote Effective Boiling" (2019). CTRC Research Publications. Paper 338.

http://dx.doi.org/https://doi.org/10.1016/j.ijheatmasstransfer.2019.02.002

This document has been made available through Purdue e-Pubs, a service of the Purdue University Libraries. Please contact epubs@purdue.edu for additional information. 


\title{
The Petal Effect of Parahydrophobic Surfaces Offers Low Receding Contact Angles that Promote Effective Boiling ${ }^{1}$
}

\author{
Taylor P. Allred ${ }^{2}$, Justin A. Weibel ${ }^{3}$, Suresh V. Garimella ${ }^{4}$ \\ School of Mechanical Engineering and Birck Nanotechnology \\ Purdue University, West Lafayette, IN 47907
}

\begin{abstract}
Despite extensive study of boiling processes and their widespread use in industry, critical interactions between the fluid and surface during boiling remain poorly understood. Simplistic, static descriptions of the contact angle are still relied upon to describe the effects of surface wettability on dynamic interfacial processes that govern boiling. This work demonstrates the critical role of the dynamic wettability characteristics of a surface on bubble growth dynamics and boiling performance. In spite of their superior nucleation behavior, hydrophobic surfaces have received little attention for boiling applications due to their typically premature transition from efficient nucleate boiling to inefficient film boiling. Evaluation of hydrophobic surfaces with high contact angle hysteresis reveals that the heat transfer efficacy of these surfaces can be exploited in boiling, so long as the receding contact angle of the surface is sufficiently small to mitigate vapor spreading and thereby extend the nucleate boiling regime. A new paradigm of textured boiling surfaces - parahydrophobic surfaces that exhibit the "petal effect" and mimic the wetting behavior of a rose petal - are shown to have untapped potential in boiling applications resulting from highly hydrophobic behavior coupled with low receding contact angles.
\end{abstract}

\section{Keywords}

Parahydrophobic; hydrophobic; nucleate boiling; wettability; critical heat flux

\footnotetext{
${ }^{1}$ Submitted for possible publication in International Journal of Heat and Mass Transfer, 2018.

${ }^{2}$ E-mail address: allredt@purdue.edu.

${ }^{3}$ E-mail address: jaweibel@purdue.edu.

${ }^{4}$ Corresponding author, Tel.: +1 765494 5621. E-mail address: sureshg@purdue.edu.
} 


\section{Introduction}

Boiling is prevalent in staple industrial processes such as distillation, power generation, and cooling. Despite the prevalence of boiling processes in industry and decades of scientific study, researchers continue to actively seek [1-3] further improvements in boiling heat transfer efficacy and accurate prediction of the sudden transition to film boiling, a catastrophic failure mechanism referred to as the critical heat flux. Current trends in high-performance computing, electric vehicles, renewable energy conversion, and telecommunications applications demand the efficient removal of high heat fluxes from surfaces maintained at a low temperature, as is afforded by boiling.

The wettability of boiling surfaces has emerged as a key factor in their heat transfer efficacy. Hydrophilic surfaces (notionally identified by a static contact angle less than $90^{\circ}$ ) and textured superhydrophilic surfaces (identified by contact angles approaching zero and capillary wicking) have been reported to delay critical heat flux through improved rewetting [4-10]; however, at lower heat fluxes in the nucleate boiling regime, they have less efficient heat transfer than hydrophobic surfaces (notionally identified by a static contact angle greater than 90 ) [11-13]. Hydrophobic surfaces exhibit boiling incipience at lower surface temperatures and yield higher nucleation site densities in the nucleate boiling regime, which leads to efficient heat transfer at low heat fluxes, but are commonly reported to promote premature film boiling leading to prohibitive surface temperatures at moderate to high heat fluxes [12,1416]. Biphilic surfaces have been developed in an effort to capitalize on the benefits of hydrophobicity while mitigating the disadvantages $[11,12,17,18]$.

Texturing hydrophobic surfaces can lead to a variety of unique boiling behaviors based on the wetting state of the water on the surface structures. While other wetting states have been proposed [19], the two most well-known are the Cassie-Baxter and the Wenzel states [20,21], which exhibit distinctly different dynamic wetting behavior [22-24]. Surfaces that can sustain a Cassie-Baxter state, in which droplets rest on top of surface structures, are considered superhydrophobic and have extreme water-repellent behavior (contact angles greater than $150^{\circ}$ and roll-off angles less than $10^{\circ}$ ) $[25,26]$; however, the Cassie-Baxter state is often metastable. If an energy barrier is overcome, the droplet sinks into the surface structures in a transition to the Wenzel state $[27,28]$. In this state, droplets also have high static contact angles, but are strongly pinned in place due to high contact angle hysteresis [22,23]. In boiling, superhydrophobic surfaces have commonly been shown to transition to film boiling upon incipience, rendering them useless in application despite having favorable incipience superheats [29-33]. Recently, however, the authors have demonstrated the ability to limit vapor spreading during boiling on superhydrophobic surfaces by bringing these surfaces into the Wenzel state prior to boiling [34]. In this state, the three-phase contact line is strongly pinned and bubbles grow with a fixed contact diameter, leading to minimal vapor coverage of the surface 
and enabling highly effective boiling up to high heat fluxes approaching Zuber's theoretical limit [35]. This result indicates that, if favorable dynamic wetting behavior can be achieved, the advantageous incipience and nucleation behavior characteristic of hydrophobic surfaces can be leveraged to improve boiling, without a detriment to critical heat flux.

This motivates the use of parahydrophobic surfaces for boiling applications. Parahydrophobic surfaces are textured hydrophobic surfaces that exhibit high static contact angles as well as high contact angle hysteresis. This wetting behavior, commonly known as the "petal effect", has recently come to the attention of the scientific community due to it being observed on natural surfaces such as the rose petal [36,37] and the peanut leaf [38], among others [39]. Water droplets placed on a parahydrophobic surface can remain adhered even when the surface is inverted, despite having contact angles approaching or exceeding $150^{\circ}$. Parahydrophobic surfaces have never been investigated for boiling applications, but have demonstrated the unique ability to pin droplets and air bubbles in place due to the high contact angle hysteresis on the surface [40], suggesting they may mitigate vapor spreading during bubble growth.

Parahydrophobic surfaces have never been investigated for boiling applications. On account of recent insights gained into the importance of dynamic wetting behavior [34], they are a promising candidate due to their demonstrated contact line pinning ability. Parahydrophobicity would seem to represent the ideal characteristics desired for boiling: its hydrophobity offers favorable incipience characteristics for efficient nucleate boiling, while its contact line pinning limits vapor spreading over the surface, thus delaying critical heat flux. Unlike superhydrophobic surfaces, parahydrophobic surfaces cannot support a low-hysteresis Cassie-Baxter state, so that there is no risk of premature film boiling.

In this study, the boiling behavior of hydrophobic surfaces with various dynamic wetting properties are investigated. Both smooth and textured surfaces are coated with polydimethylsiloxane (PDMS), a hydrophobic material with high contact angle hysteresis, and Teflon, a hydrophobic material with low contact angle hysteresis. Surfaces exhibiting wetting behavior ranging from lotus-leaf-like superhydrophobic properties to rose-petal-like parahydrophobic properties are evaluated, which allows identification of the critical factors that govern bubble dynamics and the propensity for film boiling on hydrophobic surfaces

\section{Experimental Methods}

\subsection{Surface fabrication}

All surfaces were prepared by wet-sanding a metal test block to a roughness of $400-600 \mathrm{~nm}\left(\mathrm{R}_{\mathrm{a}}\right)$ and cleaning with acetone, methanol, and isopropyl alcohol prior to any fabrication steps. All PDMS-coated and Teflon-coated surfaces were fabricated on aluminum test blocks while a copper test block was used for 
the smooth copper baseline surface. Surface textures for the parahydrophobic surfaces were fabricated via chemical etching of aluminum [41]. The surface was etched for $4 \mathrm{hr}$ in a $0.25 \mathrm{M}$ solution of $\mathrm{NaOH}$ at room temperature, then rinsed with deionized water and blown dry with nitrogen. The surface texture for the superhydrophobic surface was created via laser etching (ULS, PLS6MW, $1.06 \mu \mathrm{m}$ fiber laser). Smooth surfaces were not etched. Hydrophobic wetting properties were attained by coating the surface with lowsurface-energy polymers. For PDMS coatings, the surface was submerged for $1 \mathrm{hr}$ at room temperature in a 1:10 base to curing agent solution of PDMS diluted in hexane; the surface was removed and cured at $150^{\circ} \mathrm{C}$ for $30 \mathrm{~min}$. For Teflon coatings, the surface was submerged in a $1 \% \mathrm{wt} / \mathrm{wt}$ solution of Teflon powder dissolved in a fully-fluorinated liquid (Performance Fluid PF-5060, 3M) for $30 \mathrm{~s}$ and then cured at $150^{\circ} \mathrm{C}$ for $2 \mathrm{hr}$.

Scanning electron microscope images of each surface texture, along with that of a red Freedom hybrid tea rose for comparison of texture and wetting behavior, are presented in Figure 1. The metal surfaces were imaged using a Hitachi S-4800 Field Emission Microscope. To obtain scanning electron images of the rose petal with surface structures intact, the petal was fixed and critical point dried prior to scanning. Specimens were fixed in $2 \%$ paraformaldehyde and $2 \%$ glutaraldehyde in $0.1 \mathrm{M}$ sodium cacodylate buffer. They were then post-fixed in buffered $1 \%$ osmium tetroxide, dehydrated in a graded ethanol series, and dried in a Tousimis Autosamdri-931 critical point dryer. Dried specimens were coated with platinum in a Cressington 208HR sputter coater and imaged in a FEI Nova NanoSEM 200. 

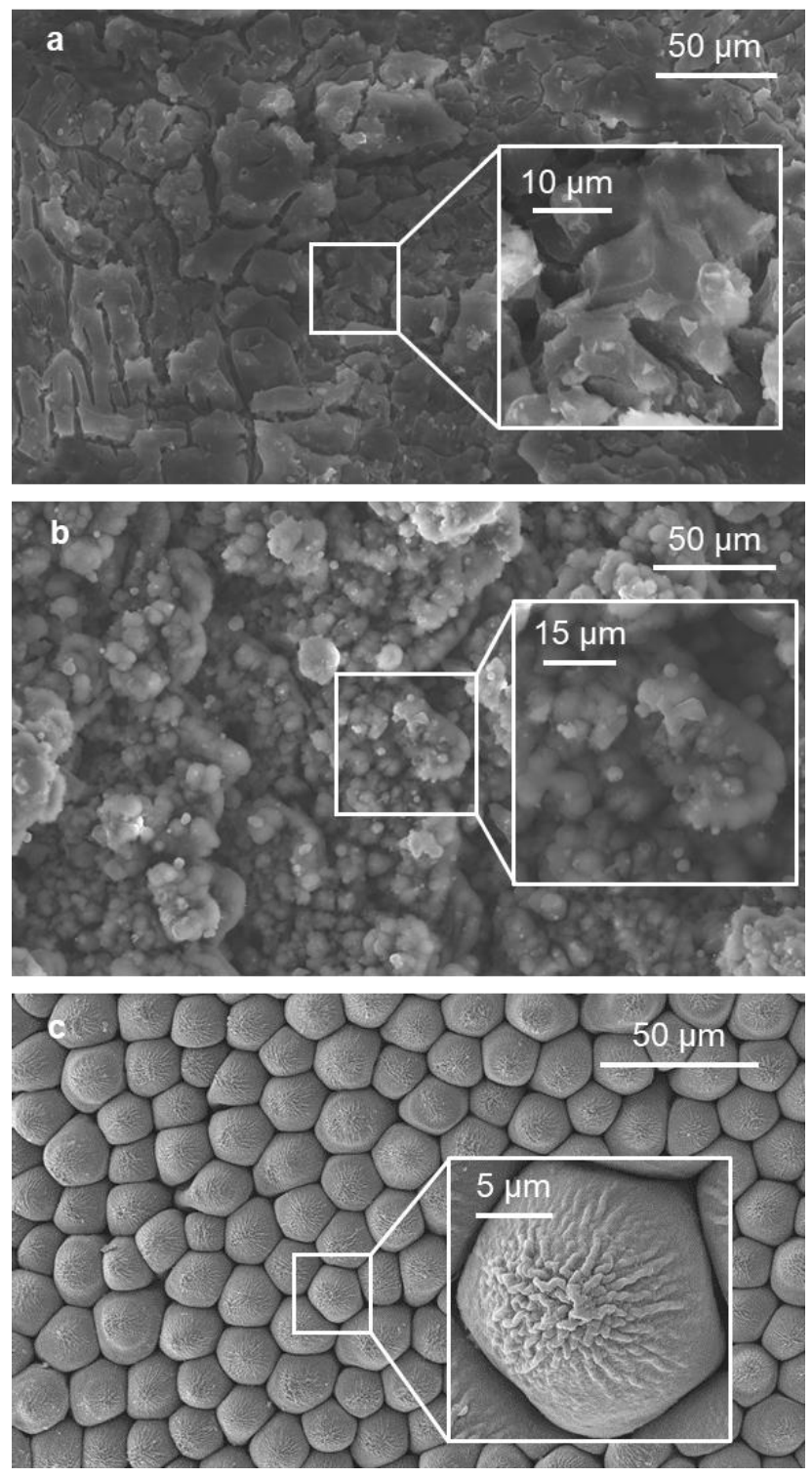

Figure 1. Scanning electron microscope images of the aluminum textured surfaces fabricated in this study. (a) Chemically-etched parahydrophobic surface texture with large (tens of microns) relatively smooth structures separated by fissures. (b) Laser-etched superhydrophobic surface texture with stochastic roughness made up of fused spheroidal particles; structures range in size from ones to tens of microns. (c) Rose petal surface with micron-sized ridges on top of microscale bumps on the order of tens of microns.

\subsection{Wetting Characterization}

The wettability of each surface was characterized by static, advancing, and receding contact angles, with the measured values reported in Table 1 . Static contact angles were measured by gently depositing a $5 \mu \mathrm{L}$ droplet on the surface and measuring the angle with the solid surface using an automated goniometer 
(ramé-hart, 290-F1). Advancing and receding contact angle measurements were obtained via the same goniometer by inserting a $0.3 \mathrm{~mm}$ outer-diameter stainless steel syringe tip into the $5 \mu \mathrm{L}$ droplet and adding or removing liquid in $0.25 \mu \mathrm{L}$ increments until a steady contact angle was observed. In the case of the textured surfaces with low receding contact angle, stick slip behavior was observed during dynamic contact angle measurements which prevented the formation of a steady receding contact angle, as reported by He et al. [23]. In this case, the lowest receding contact angle observed before the droplet became too small to accurately measure is reported. For the parahydrophobic surfaces, an additional test was performed to evaluate the adhesion of a droplet to the surface. A $5 \mu \mathrm{L}$ droplet was gently placed on the surface. The surface was then tilted to $90^{\circ}$ to see if the droplet remains adhered. The wettability of PDMS has been observed to change after boiling in water [42]. We observed that the wettability of PDMS changes significantly within the first hour of boiling and then remains stable. Thus, the contact angles reported are those of a representative surface after being subjected to boiling water for $2 \mathrm{hr}$. For all other surfaces, the wettability did not change significantly after boiling and pre-test contact angles are reported. The wetting properties of the parahydrophobic surfaces were also compared with a red Freedom hybrid tea rose, which was characterized in the same manner.

Table 1. Average contact angle measurements for each surface studied.

\begin{tabular}{ccccc}
\hline & $\begin{array}{c}\text { static } \\
\text { contact angle }\end{array}$ & $\begin{array}{c}\text { receding } \\
\text { contact angle }\end{array}$ & $\begin{array}{c}\text { advancing } \\
\text { contact angle }\end{array}$ & $\begin{array}{c}\text { contact angle } \\
\text { hysteresis }\end{array}$ \\
\hline smooth copper & $52^{\circ}$ & $\sim 10^{\circ}$ & $66^{\circ}$ & $56^{\circ}$ \\
smooth PDMS & $106^{\circ}$ & $\sim 10^{\circ}$ & $110^{\circ}$ & $100^{\circ}$ \\
smooth Teflon & $123^{\circ}$ & $111^{\circ}$ & $129^{\circ}$ & $18^{\circ}$ \\
$\quad \begin{array}{c}\circ \\
\text { rose petal }\end{array}$ & $145^{\circ}$ & $\sim 30^{\circ}$ & $154^{\circ}$ & $\sim 120^{\circ}$ \\
$\begin{array}{c}\text { parahydrophobic } \\
\text { PDMS }\end{array}$ & $144^{\circ}$ & $\sim 30^{\circ}$ & $161^{\circ}$ & $\sim 130^{\circ}$ \\
$\begin{array}{c}\text { superhydrophobic } \\
\text { PDMS }\end{array}$ & $151^{\circ}$ & $147^{\circ}$ & $156^{\circ}$ & $9^{\circ}$ \\
parahydrophobic & $135^{\circ}$ & $105^{\circ}$ & $146^{\circ}$ & $41^{\circ}$ \\
Teflon & & & & \\
\hline
\end{tabular}

\subsection{Experimental Design}

Boiling experiments were carried out in a closed-chamber pool boiling facility (Figure 2(a)). The facility and experimental procedure, previously described in Ref. [34], are briefly summarized here. The facility consists of a closed boiling chamber, an external Graham condenser used during degassing, two internal immersion heaters to maintain saturated conditions, an internal coiled condenser to maintain constant pressure during sealed operation, and temperature and pressure sensors to measure the conditions inside the chamber. Prior to the boiling test, the chamber is filled with deionized water which is then 
degassed by initially heating the test surface to the boiling point via twelve $150 \mathrm{~W}$ cartridge heaters inserted into the base of the test block and then bringing the pool to saturation using the immersion heaters. The test surface and the immersion heaters are allowed to boil $(\sim 1 \mathrm{hr})$ and noncondensibles are purged from the chamber through the Graham condenser. This degassing procedure, which boils the surface while air is still trapped in the surface, maintains the Cassie-Baxter wetting state for the superhydrophobic surfaces; the procedure is chosen to assess whether parahydrophobic surfaces will exhibit the Cassie-Baxter state during boiling, which would promote premature film boiling. After degassing, the chamber is sealed, boiling continues from the immersion heaters to maintain uniform saturated conditions, and the test surface is allowed to cool to just below the saturation temperature. The input heat flux to the test block is raised in increments of $10 \mathrm{~W} / \mathrm{cm}^{2}$ during nucleate boiling and $5 \mathrm{~W} / \mathrm{cm}^{2}$ during film boiling. For film boiling cases, the test is stopped after the surface temperature exceeds $145^{\circ} \mathrm{C}$. For nucleate boiling cases, the test continues until critical heat flux is reached, at which point the power is cut off and the system is allowed to cool. The critical heat flux value is determined based on the transient data immediately prior to the rapid temperature excursion.
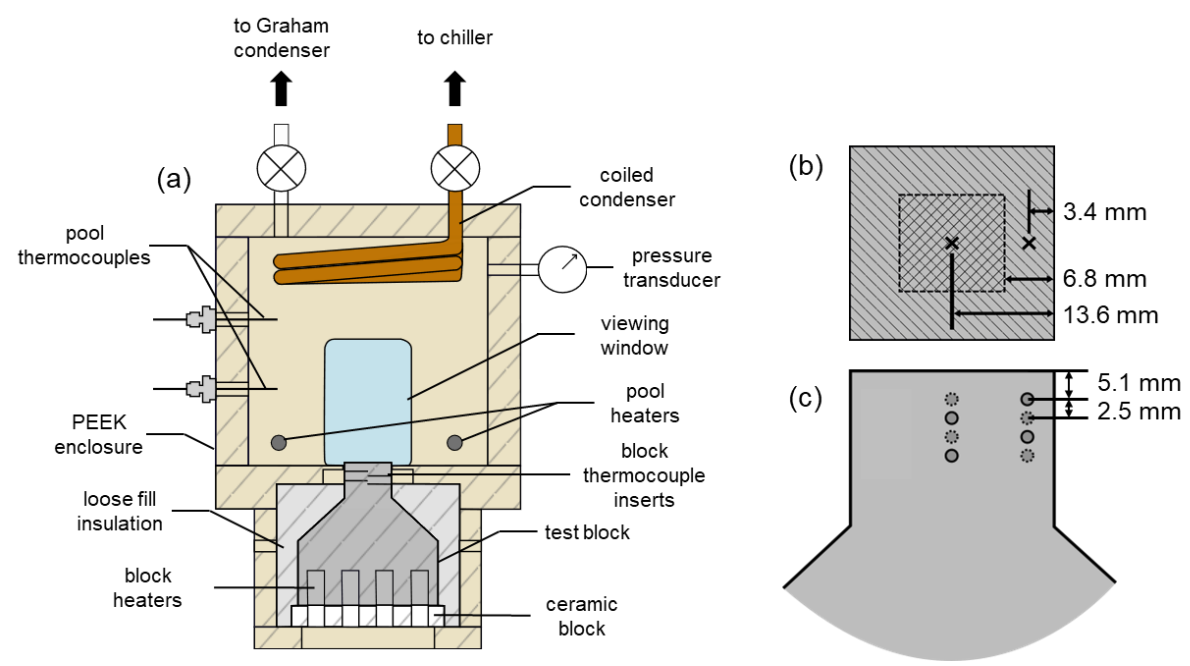

Figure 2. Schematic illustration of (a) the pool boiling test facility and (b)-(c) test block. (b) top-down view of the thermocouple locations and the surface footprint area corresponding to each thermocouple rake; and (c) side-view of the thermocouple rakes with vertical dimensions.

\subsection{Uncertainty Analysis and Data Reduction}

During the boiling experiments, temperature and pressure data is collected for each steady state point, defined as the surface temperature changing by less than $0.25^{\circ} \mathrm{C} / \mathrm{hr}$. For each steady-state point, the temperature and pressure data are averaged over $\sim 75 \mathrm{sec}$. The pressure is used to determine the saturation 
temperature of the water. The surface temperature and heat flux are determined from the spatial temperature gradient measured along two vertical thermocouple rakes with four thermocouples each, arranged as shown in Figure 2(c). The linear least-squared fit to the spatial temperature gradient and thermal conductivity of the metal $(167 \mathrm{~W} / \mathrm{mK}$ and $390 \mathrm{~W} / \mathrm{mK}$ for aluminum and copper, respectively) are used to determine the heat flux based on Fourier's law. The surface temperature is determined by extrapolating the gradient to the surface location. The area-averaged surface temperature and heat flux are determined by taking an areaweighted average of the surface temperature and heat flux obtained from each thermocouple rake. The areas that correlate to each thermocouple rake are shown in Figure 2(b), which correspond to area-based weights of 0.25 for the central rake and 0.75 for the side rake for each block. The surface superheat is determined as the difference between the area-averaged surface temperature and the saturation temperature of the water. The heat transfer coefficient, a measure of the boiling heat transfer efficiency, is calculated by dividing the heat flux by the surface superheat at a steady state point.

Uncertainties of the heat flux, surface superheat, and heat transfer coefficient are assessed. Ice-pointreferenced thermocouples were all calibrated simultaneously in a dry-block calibrator (Isotech, Jupiter 4852) over a temperature range of $50^{\circ} \mathrm{C}$ to $250^{\circ} \mathrm{C}$. An RTD is used to accurately measure the dry block temperature during the calibration. The manufacturer-quoted uncertainty for the RTD is $\pm 0.15 \mathrm{~K}$ and the ice point uncertainty is $\pm 0.05 \mathrm{~K}$. A linear offset from the NIST ITS-90 standard is fitted to the calibration data for each thermocouple. The uncertainty in this linear calibration curve is determined through analyzing the regression uncertainty [43]. Because the results are averaged over many data points, random errors are neglected; the uncertainties are assumed to vary independently, eliminating the covariance uncertainties. The thermocouple uncertainty was determined to be approximately $\pm 0.35^{\circ} \mathrm{C}$.

The heat flux and surface temperature uncertainties are determined based on the uncertainty of the linear regression [43] of the temperature gradient along the thermocouple rakes, taking into account the temperature measurement uncertainty $\left( \pm 0.35^{\circ} \mathrm{C}\right)$ and the positional uncertainty of each thermocouple \pm 0.04 $\mathrm{mm}$. The uncertainty of the slope and intercept of the linear fit correlates directly to the heat flux and surface temperature. The heat flux uncertainty generally increases with heat flux and the maximum uncertainty was $2.9 \mathrm{~W} / \mathrm{cm}^{2}$. The uncertainty in the saturation temperature, based on the pressure transducer measurement uncertainty, is $\pm 0.12^{\circ} \mathrm{C}$. The surface superheat uncertainty, which depends on both the surface and saturation temperature uncertainties, ranges from $0.52{ }^{\circ} \mathrm{C}$ to $0.66^{\circ} \mathrm{C}$.

\subsection{Visualization and Bubble Diameter Measurements}

Bubble departure diameters and maximum base diameters were measured directly from high-speed videos (Phantom, VEO 710L) taken during boiling, with pixel size calibrated based on the known surface width. For each surface, a high-speed video was recorded immediately after boiling incipience. The 
diameters are reported based on the average of measurements taken from the first unobscured nucleation site that activates on the interior of the surface and does not coalescing with other sites during the bubble ebullition cycle. For surfaces with repeated bubble departures from the same initial nucleation site (smooth PDMS and smooth copper), departure diameters and maximum base diameters were observed to vary by less than $10 \%$. On the smooth Teflon surface, due to the long ebullition cycle and surface-level coalescence, only one isolated bubble departure was observed.

\section{Results and Discussion}

\subsection{Critical role of receding contact angle on the boiling behavior of smooth hydrophobic surfaces}

Boiling experiments with smooth surfaces were carried out to determine the impact of the unique wetting behavior of two different hydrophobic coating materials in comparison with a hydrophilic copper baseline. The boiling curves for each of these surfaces (smooth copper, smooth PDMS-coated, and smooth Teflon-coated), along with the static and receding contact angle measurements (wetting characterization measurements detailed in Experimental Section), are shown in Figure 3. The hydrophilic copper baseline surface, having a static contact angle of $52^{\circ}$ and a receding angle of $\sim 10^{\circ}$, behaves as expected, exhibiting nucleate boiling behavior and reaching critical heat flux near Zuber's predicted limit [35]. The PDMS-coated surface has a high static contact angle $\left(106^{\circ}\right)$, but a similarly low receding contact angle $\left(\sim 10^{\circ}\right)$. This surface sustains nucleate boiling and a cooler surface temperature than the baseline copper surface at all steady-state points on the boiling curve and reaches a similar critical heat flux. The Teflon-coated surface has high static and receding contact angles ( $123^{\circ}$ and $111^{\circ}$, respectively). This surface exhibits low-temperature boiling incipience, but transitions to film-like boiling shortly after incipience, resulting in very high superheats as the heat flux is increased.

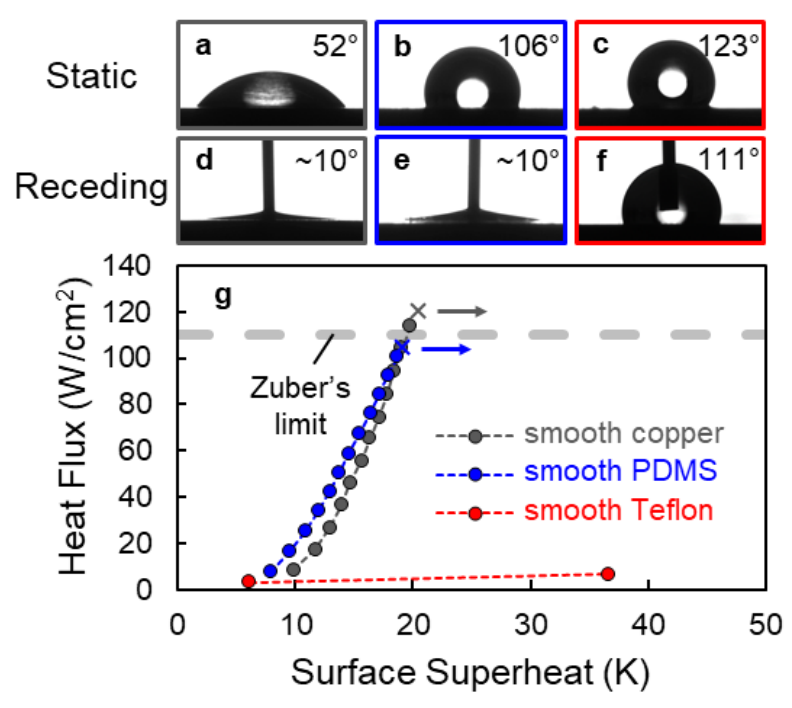


Figure 3. Wettability characterization and boiling results for smooth hydrophilic and hydrophobic surfaces. Static $5 \mu \mathrm{L}$ droplets on (a) smooth copper, (b) smooth PDMS-coated, and (c) smooth Teflon-coated surfaces. Receding droplets on (d) smooth copper, (e) smooth PDMS-coated, and (f) smooth Teflon-coated surfaces. (g) Boiling curves (heat flux versus surface superheat) for each of the smooth surfaces. Calculated uncertainties in heat flux and surface superheat are less than $3 \mathrm{~W} / \mathrm{cm}^{2}$ and $0.7 \mathrm{~K}$, respectively. Crosses with a rightward arrow indicate critical heat flux and subsequent temperature excursions. The horizontal dashed line indicates the critical heat flux predicted by Zuber's proposed hydrodynamic limit [35].

The boiling behavior at a low heat flux below $10 \mathrm{~W} / \mathrm{cm}^{2}$ is shown for each of these smooth surfaces in Figure 4. The different vapor formation characteristics that result in the differing boiling performance of the surfaces are evident. The copper and PDMS-coated surfaces both exhibit nucleate boiling; more active nucleation sites are observed on the hydrophobic PDMS-coated surface, resulting in a lower surface superheat $(7.9 \mathrm{~K})$ on this surface compared to the smooth copper $(9.9 \mathrm{~K})$. The Teflon-coated surface is blanketed in insulating vapor, resulting in high surface superheats. Remarkably, even though the two hydrophobic PDMS-coated and Teflon-coated surfaces have similar wettability in terms of the static contact angle, their boiling behavior is drastically different. The bubble dynamics observed on the PDMS-coated surface align more closely with the hydrophilic baseline surface. 


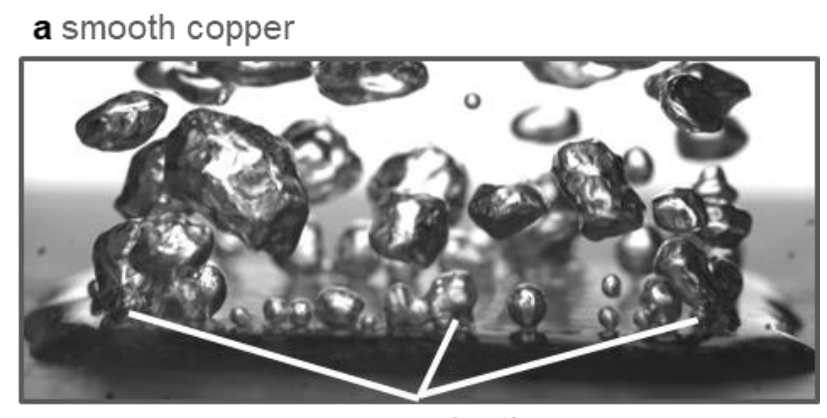

sparse nucleation

b smooth PDMS

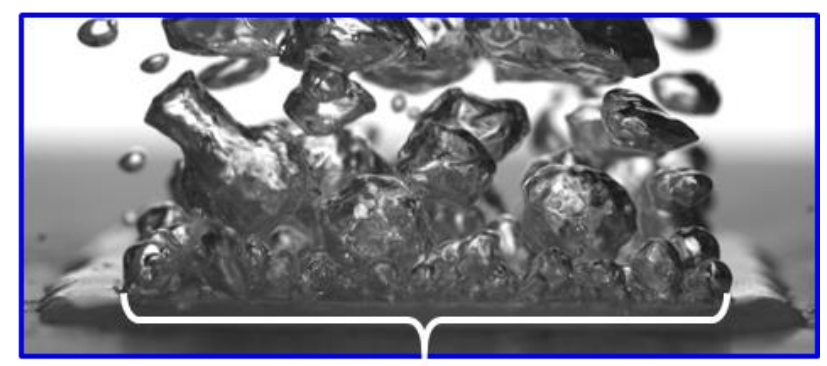

dense nucleate boiling across surface c smooth Teflon

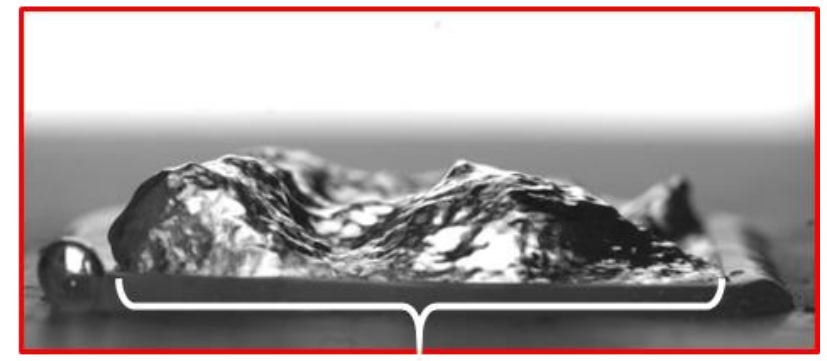

full vapor coverage

Figure 4. Images comparing the boiling behavior on smooth surfaces. (a) Sparse nucleate boiling from the smooth copper surface (heat flux: $8.3 \mathrm{~W} / \mathrm{cm}^{2}$; superheat: $9.9 \mathrm{~K}$ ), (b) dense nucleate boiling from the smooth PDMS-coated surface $\left(7.5 \mathrm{~W} / \mathrm{cm}^{2} ; 7.9 \mathrm{~K}\right)$, and (c) film boiling from the smooth Teflon-coated surface $(6.7$ $\left.\mathrm{W} / \mathrm{cm}^{2} ; 36.7 \mathrm{~K}\right)$. For high-speed videos of the boiling behavior, refer to Appendix A.

As a bubble grows and the contact line expands outward from the nucleation site, the liquid is receding away. Thus, the receding contact angle could logically be expected to play a dominant role in the dynamics of bubble growth, as suggested by Chen et al. [44]. The importance of the receding contact angle is clearly demonstrated in the single bubble dynamics at incipience, shown in Figure 5. The bubble behavior on the PDMS-coated and Teflon-coated surfaces is drastically different despite their similar static contact angles $\left(106^{\circ}\right.$ and $123^{\circ}$, respectively). On both surfaces, the contact angle of a receding droplet (Figure 5(a) and Figure 5(d)) closely matches the contact angle of liquid receding away from the site of a growing bubble 
(Figure 5(b) and Figure 5(e)) during the early stages of bubble growth before buoyancy begins to distort the bubble shape. As a result, on the PDMS-coated surface, the base diameter of the bubble remains small during low-receding-angle growth (Figure 5(c)), which allows most of the surface to remain wetted. Once the bubble becomes large enough, buoyancy forces exceed the surface tension forces and the bubble departs. The minimal dewetting that occurs during bubble growth allows the notionally hydrophobic PDMS-coated surface to maintain nucleate boiling. It is important to note that the PDMS-coated surface is uniformly hydrophobic; thus, the governing mechanisms that prevent vapor spreading over the surface differ from those of biphilic surfaces which prevent spreading by pinning the contact line at distinct surface wettability heterogeneities. On the Teflon-coated surface, the base diameter of the bubble spreads as the bubble grows with a high receding contact angle (Figure 5(f)). A single bubble reaches a base diameter of several millimeters, covering a large area of the surface with vapor prior to departure. Once the bubble has reached some maximum base diameter, the bubble stretches upward due to buoyancy as it continues to grow and the liquid-vapor interface becomes nearly perpendicular to the solid surface as the bubble shape becomes dominated by buoyancy effects. The base diameter begins to recede, followed by the bubble departing by pinching off above the surface, leaving behind a small vapor bubble. Due to the extensive vapor spreading during bubble growth, active nucleation sites readily coalesce resulting in premature film boiling at a low heat flux.

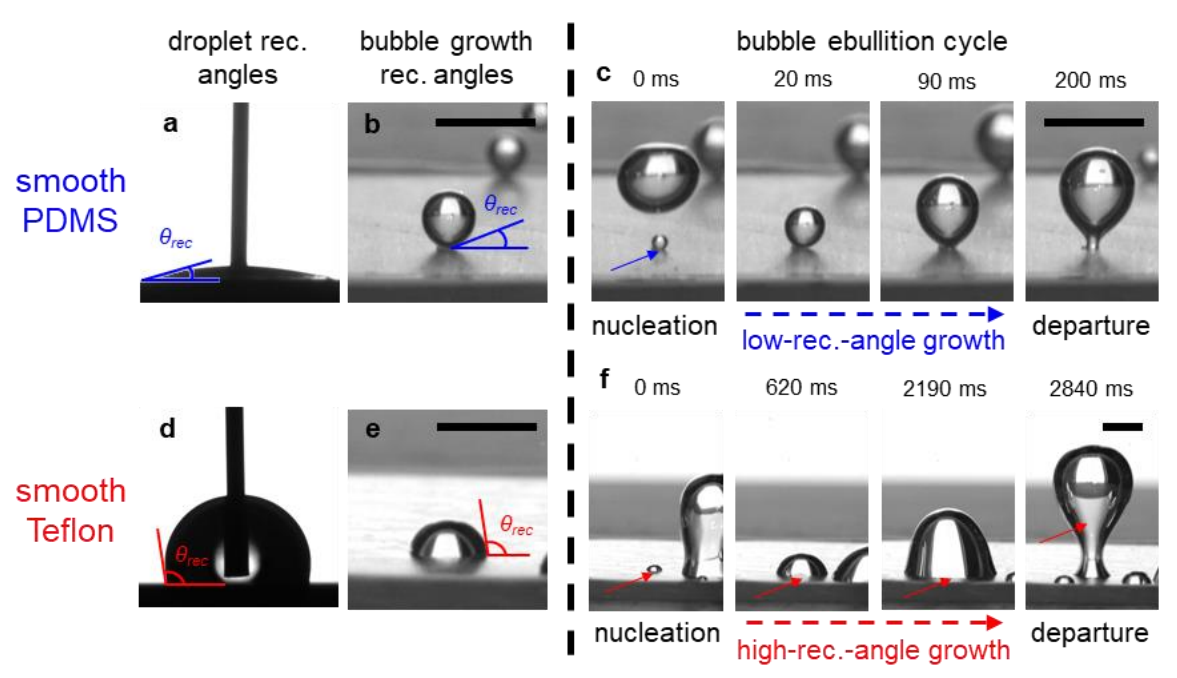

Figure 5. Bubble growth dynamics and ebullition cycle. (a) Receding contact angle measurement of a droplet on the smooth PDMS-coated surface and (b) image showing a similarly small receding contact angle during bubble growth on the same surface. (c) Bubble ebullition cycle on a PDMS-coated surface exhibiting low-receding-angle growth. (d) Receding contact angle measurement of a droplet on the Tefloncoated surface and (e) image of a growing bubble on the same surface showing a similarly large receding 
contact angle. (f) Bubble ebullition cycle on a Teflon-coated surface exhibiting high-receding-angle growth. Scale bars, $3 \mathrm{~mm}$. Note the different length and time scales indicated on (c) and (f). For high-speed videos of the bubble dynamics, refer to Appendix A.

\subsection{Model for receding contact angle governed bubble growth}

To explain the role of the receding contact angle during bubble growth, a simple analytical model is derived to predict the bubble departure diameter and maximum base diameter. The model compares the buoyancy force acting on the bubble $\left(F_{b}=\left(\rho_{l}-\rho_{g}\right) V g\right.$, where $\rho_{l}$ and $\rho_{g}$ are the densities of the liquid and vapor, $V$ the bubble volume, and $g$ the gravitational constant) with the vertical component of the surface tension force acting at the three-phase contact line $\left(F_{s}=\gamma\left(\pi D_{b}\right) \sin \theta\right.$, where $\gamma$ is the liquid-vapor surface tension, $D_{b}$ the base diameter of the bubble, and $\theta$ the contact angle). A complete derivation of the model and expressions for the bubble departure diameter $\left(D_{\text {depart }}\right)$ and maximum base diameter $\left(D_{b, \max }\right)$ are presented in Appendix B.

For a surface with a low receding contact angle (less than $90^{\circ}$ ), the bubble growth progression can be approximated as illustrated in Figure 6(a)-(c). The bubble grows as a spherical cap with the liquid at the receding contact angle until it reaches a critical size at which the buoyancy and surface tension forces are balanced (Figure 6(a)). Then, the base diameter begins to retract as the bubble begins to rise (Figure 6(b)), and ultimately departs from the surface as a sphere (Figure 6(c)). Based on this progression, the maximum vertical component of the surface tension forces occurs when the buoyancy and surface tension forces first become balanced (Figure 6(a)). Thus, the maximum base diameter and departure diameter of the bubble can be determined by equating the buoyancy and surface tension forces in this configuration, assuming a spherical cap geometry at the receding contact angle. This results in a trend of increasing bubble departure diameter and maximum base diameter with increasing receding contact angle from 0 to $90^{\circ}$, as shown in Figure 6(g).

For a surface with a high receding contact angle (greater than $90^{\circ}$ ), the bubble growth progression can be approximated as illustrated in Figure 6(d)-(f). The bubble grows as a spherical cap at the receding contact angle until it reaches a size at which the buoyancy force and the vertical component of the surface tension force become balanced (Figure 6(d)). The bubble base diameter begins to retract and the bubble begins to deform upward due to buoyancy effects (Figure 6(e)). As a result, the liquid contact angle decreases, causing the vertical component of the surface tension forces to increase as the bubble continues to grow. Ultimately, the bubble departs by pinching-off just above the surface, leaving behind a small vapor bubble on the surface (Figure 6(f)). Because of the pinch-off mechanism, the limiting surface tension force, after which departure process begins via the retracting of the diameter at the pinch-off height, is expected to 
occur at the point where the interface is perpendicular to the surface. Thus, the bubble size is determined based on the elongated bubble represented by Figure 6(e), with the interface assumed to be perpendicular to the surface at the height at which the pinch-off occurs. The departure volume, from which the departure diameter is trivially obtained, is determined by a balance of the buoyancy and surface tension forces at an arbitrary pinch-off height, assuming the bubble above the pinch-off height can be approximated as a spherical cap and the volume below the pinch-off location remains on the surface. Because the limiting surface tension forces occur at an angle perpendicular to the surface rather than at the receding contact angle, all surfaces with a receding contact angle greater than $90^{\circ}$ are predicted to have the same departure diameter. The maximum base diameter is estimated by considering the volume of the departed bubble as a spherical cap with a contact angle equal to the receding contact angle, resulting in an increasing trend in maximum base diameter with increasing receding contact angle above $90^{\circ}$; this is expected to be an overestimate due to neglect of the bubble deformation by buoyancy.

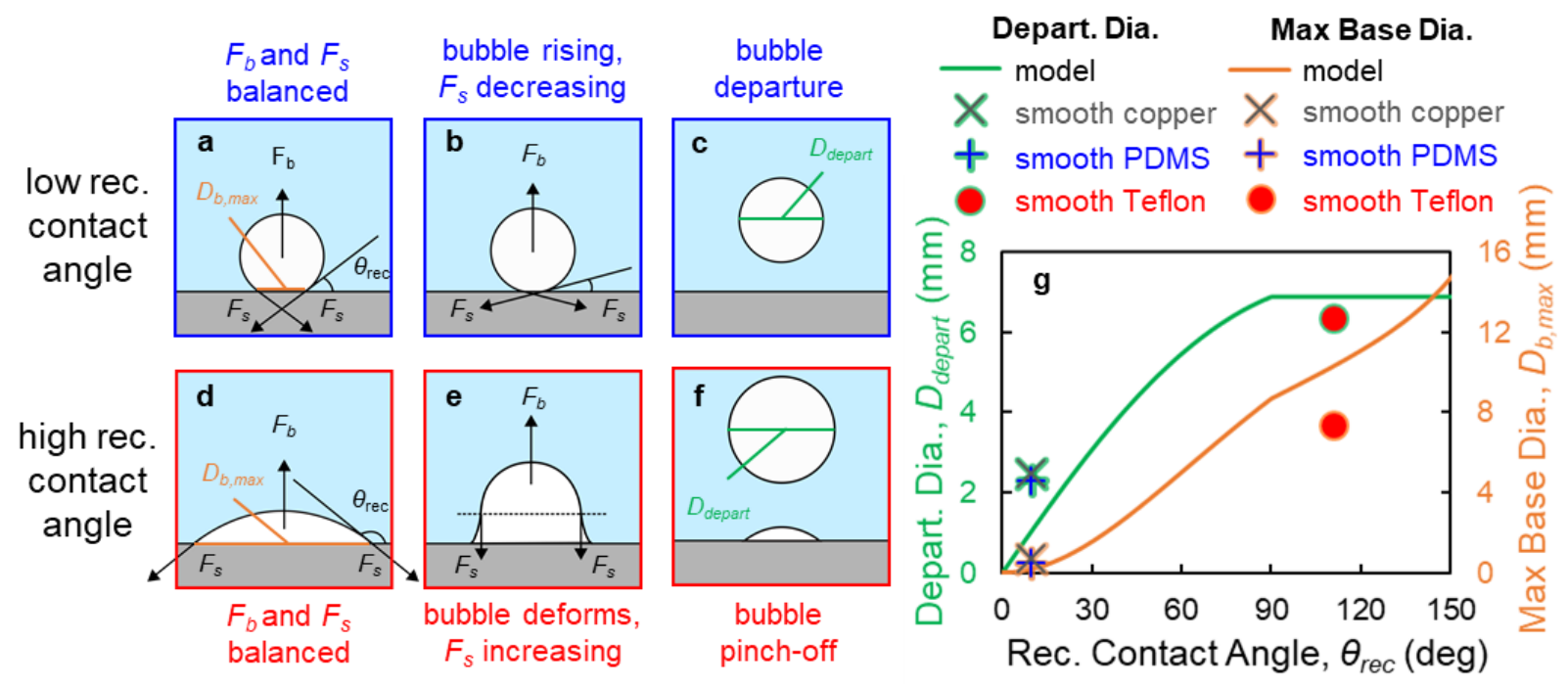

Figure 6. Illustration of approximate bubble growth progressions and results of bubble growth model. Bubble growth and departure on a surface with (a)-(c) low receding contact angle and (d)-(f) high receding contact angle. (g) Model results for the bubble departure diameter and maximum bubble base diameter plotted along with experimental results from the smooth surfaces.

The experimental results closely follow the trends of bubble departure diameter and base diameter with increasing receding contact angle and match the expected magnitudes, as shown in Figure 6(g). The model slightly underpredicts the departure diameter on a surface with a low receding contact angle and, as expected, overpredicts the maximum base diameter on a surface with a high receding contact angle. This 
agreement confirms the dominant role of the receding contact angle on bubble growth and departure dynamics.

\subsection{Texturing hydrophobic surfaces for efficient boiling heat transfer}

This newfound understanding that the receding contact angle governs bubble growth dynamics is next used to design textured hydrophobic surfaces that provide favorable bubble dynamics to avoid premature critical heat flux while further enhancing nucleate boiling. Based on the results discussed above for smooth surfaces, it is evident that previously observed vapor spreading on hydrophobic surfaces [12,15,29-33] can be mitigated by minimizing the receding contact angle of the surface. To further demonstrate this understanding, the wettability characteristics and boiling performance of a high-hysteresis parahydrophobic surface versus a low-hysteresis superhydrophobic surface (in the Cassie-Baxter state) are reported in Figure 7. These surfaces feature the same PDMS coating material, but different textures give rise to their drastically different dynamic wetting behaviors. The parahydrophobic PDMS-coated surface, which is textured to provide wetting properties similar to those of the rose petal (as shown in Figure 7), has a high static contact angle $\left(144^{\circ}\right)$ and a low receding contact angle $\left(\sim 30^{\circ}\right)$. Due to the high contact angle hysteresis, a $5 \mu \mathrm{L}$ droplet deposited on this surface remains adhered even when tilted at a $90^{\circ}$ angle or inverted. Textured to minimize contact angle hysteresis, the superhydrophobic PDMS-coated surface also has a high static contact angle $\left(151^{\circ}\right)$, but paired with a high receding contact angle $\left(147^{\circ}\right)$. Due to the minimal contact angle hysteresis, droplets readily roll off this surface when tilted, similar to the classical behavior of the lotus leaf [45].

As hypothesized, the contrast in the receding contact angles results in stark differences in the boiling behavior and heat transfer performance. The superhydrophobic PDMS-coated surface exhibits film boiling behavior immediately upon incipience and throughout the boiling curve, resulting in large surface superheat increases with small increases in heat flux. The parahydrophobic PDMS-coated surface maintains nucleate boiling to a high heat flux and even further reduces surface temperatures compared to the smooth PDMScoated surface; at a low heat flux of $\sim 8 \mathrm{~W} / \mathrm{cm}^{2}$, a $60 \%$ increase in the heat transfer coefficient (heat flux divided by surface superheat) is observed compared to the smooth copper surface. 


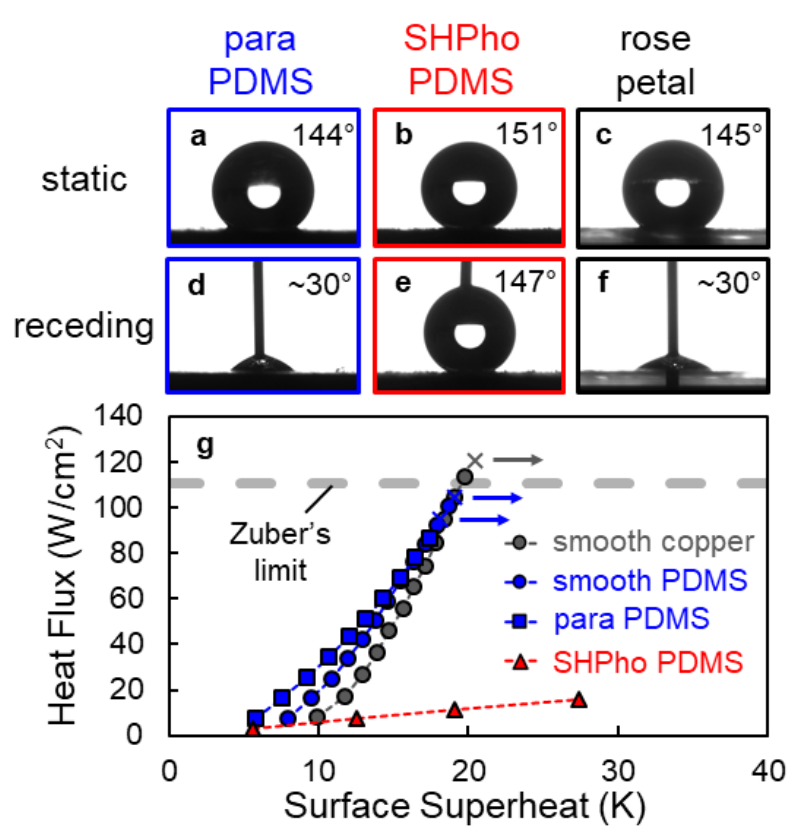

Figure 7. Wettability characterization and boiling results for textured PDMS-coated surfaces. Static $5 \mu \mathrm{L}$ droplets on (a) parahydrophobic PDMS-coated surface (para PDMS), (b) superhydrophobic PDMScoated surface (SHPho PDMS), and (c) rose petal. Receding droplets on (d) parahydrophobic PDMScoated surface, (e) superhydrophobic PDMS-coated surface, and (f) rose petal. (g) Boiling curves (heat flux versus surface superheat) for the textured PDMS-coated surfaces compared with the smooth copper and PDMS-coated surfaces. Calculated uncertainties in heat flux and superheat are less than $3 \mathrm{~W} / \mathrm{cm}^{2}$ and $0.7 \mathrm{~K}$, respectively. Crosses with a rightward arrow indicate critical heat flux and subsequent temperature excursions. The horizontal dashed line indicates the critical heat flux predicted by Zuber's proposed hydrodynamic limit [35].

By tailoring the wettability to resemble that of the rose petal, the boiling performance is enhanced considerably due to favorable bubble dynamics. As presented in Figure 8, the low receding contact angle characteristic of the parahydrophobic PDMS-coated surface minimizes the bubble base diameter during bubble growth; tiny bubbles have a near-perfect spherical shape as they grow and readily depart from the surface (Figure 8(a)). This behavior sustains nucleate boiling even under conditions with dense, vigorous vapor formation across the entire surface by minimizing surface dewetting (Figure 8(b)). On the superhydrophobic surface, the base diameter of the bubbles spreads freely as the bubble grows at the receding contact angle. As a result, the first bubble that forms covers much of the surface in vapor and extensive surface-level coalescence occurs prior to a single bubble departure (Figure 8(c)). Due to the promotion of the Cassie-Baxter state, this region traps vapor in the interstices of the surface structures and 
is never able to rewet. Thus, the surface becomes blanketed in vapor easily, resulting in premature film boiling (Figure $8(d)$ ).

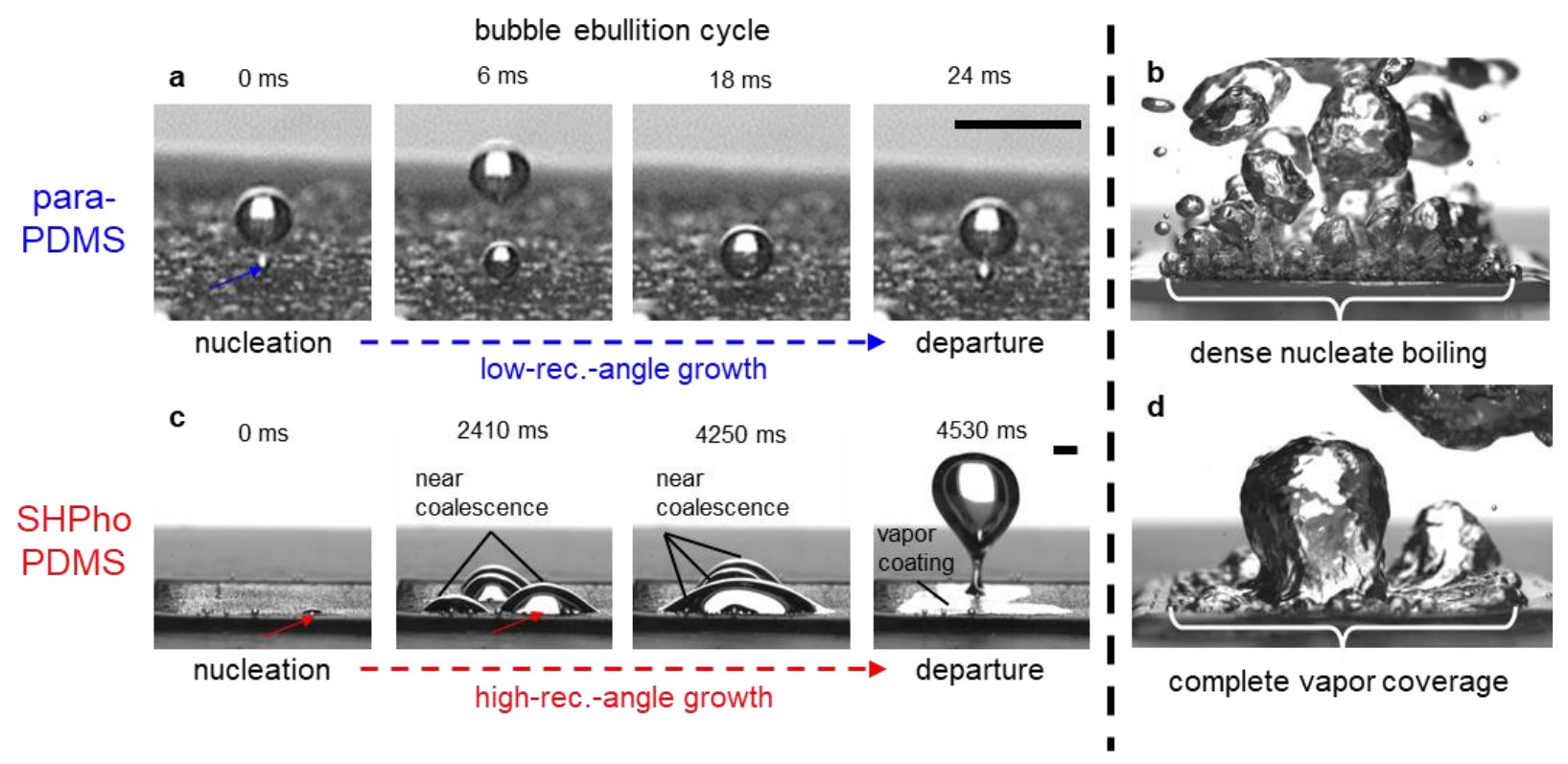

Figure 8. Comparison of the bubble ebullition cycle and boiling behavior of the textured PDMS-coated surfaces. (a) Bubble ebullition cycle on the parahydrophobic PDMS-coated and (c) growth, coalescence and departure of first bubbles on the superhydrophobic PDMS-coated surface at incipience. Low-heat-flux boiling behavior of (b) the parahydrophobic PDMS-coated surface (heat flux: $7.8 \mathrm{~W} / \mathrm{cm}^{2}$; superheat: $5.8 \mathrm{~K}$ ) and (d) the superhydrophobic PDMS-coated surface $\left(7.3 \mathrm{~W} / \mathrm{cm}^{2} ; 12.5 \mathrm{~K}\right)$. Scale bars, $2 \mathrm{~mm}$. For high-speed videos of the bubble dynamics, refer to Appendix A.

In a recent study by the authors [34], superhydrophobic surfaces were shown to promote effective nucleate boiling if brought into the Wenzel state prior to boiling, but to suffer ineffective film boiling if in the Cassie-Baxter state prior to boiling. The initial wetting state on the surface in Ref. [34] was controlled via the degassing procedure. Importantly, the parahydrophobic PDMS-coated surface in the current study maintains nucleate boiling even under conditions that promote a Cassie-Baxter wetting state on superhydrophobic surfaces. Parahydrophobic surfaces can thereby remove the risk of premature film boiling, because they do not support a Cassie-Baxter wetting state. These surfaces capitalize upon the advantages of hydrophobicity (i.e., promotion of boiling incipience at low superheats and high nucleation site densities that yield efficient heat transfer) while mitigating the vapor spreading and premature film boiling that commonly plague hydrophobic boiling surfaces. Compared with biphilic surfaces that have small, isolated hydrophobic regions, parahydrophobic surfaces may be capable of greater improvement to 
the heat transfer coefficient due to utilization of the entirety of the surface for enhanced nucleation. With further geometric optimization of the texture geometry to promote nucleation and reduce the receding contact angle, parahydrophobic surfaces offer a very promising approach to minimize surface temperatures during boiling without negatively affecting the critical heat flux.

We caution that a surface satisfying the notional criteria for 'parahydrophobicity' does not automatically ensure that it will yield advantageous boiling characteristics. There is no consensus in the research community on the specific wetting characteristics that define parahydrophobicity, but a surface is typically regarded as being parahydrophobic if it has a high static contact angle (approaching or exceeding $150^{\circ}$ ) and a droplet can remain adhered to the surface when tilted at $90^{\circ}$ or inverted. Because adhesion of a droplet to a surface when tilted is governed by the contact angle hysteresis, all notionally parahydrophobic surfaces do not necessarily possess the low receding contact angle required for maintaining nucleate boiling. This is demonstrated next by evaluating the boiling performance of a parahydrophobic Teflon-coated surface with the same textured surface morphology as the parahydrophobic PDMS-coated surface, presented in Figure 9(d). Like the rose petal and the parahydrophobic PDMS-coated surface (Figure 9(a) and Figure 9(c), respectively), the Teflon-coated surface is considered parahydrophobic owing to a high static contact angle $\left(135^{\circ}\right.$ ) and the adherence of a $5 \mu \mathrm{L}$ droplet to the surface when tilted at $90^{\circ}$ (attributable to a high contact angle hysteresis of $\sim 40^{\circ}$ ), shown in Figure 9(b). However, unlike for a PDMS coating, the parahydrophobic Teflon-coated surface has a high receding contact angle $\left(105^{\circ}\right)$ and was observed to undergo premature film boiling (see Appendix A for a high-speed video of this behavior), resulting in significant increases in surface superheat with increasing heat flux. This reinforces the assertion that the receding contact angle governs vapor spreading during boiling, rather than the contact angle hysteresis which is used to identify parahydrophobicity. 


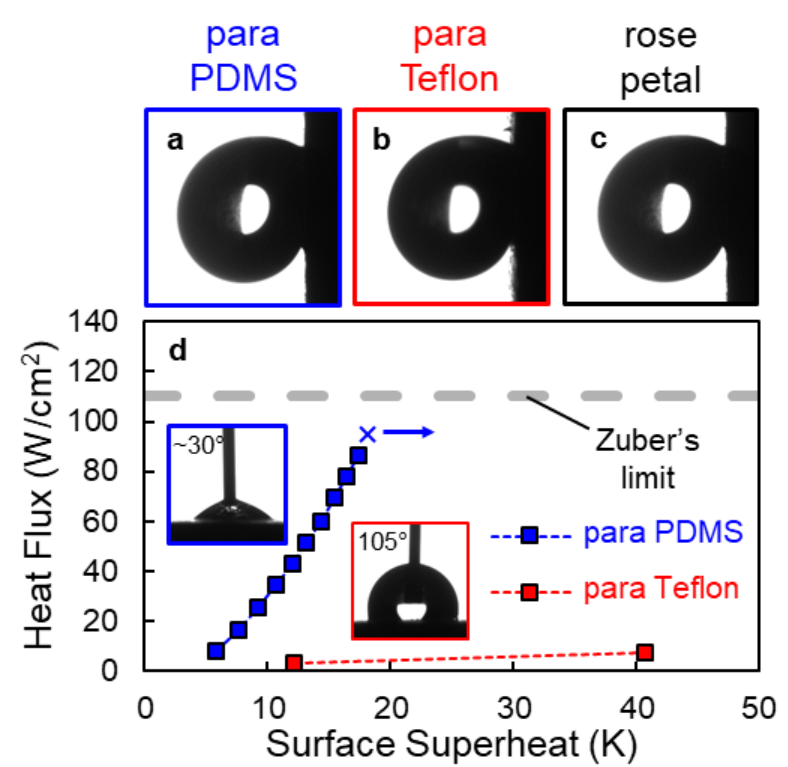

Figure 9. Wetting behavior and boiling results for parahydrophobic PDMS-coated (para PDMS) and Teflon-coated (para Teflon) surfaces. A $5 \mu \mathrm{L}$ droplet adhered to (a) parahydrophobic PDMS-coated surface, (b) parahydrophobic Teflon-coated surface, and (c) rose petal while tilted at $90^{\circ}$. (d) Boiling curves (heat flux versus surface superheat) for the two parahydrophobic surfaces with insets showing the receding contact angle measurements for each surface. Calculated uncertainty for the heat flux and superheat are less than $3 \mathrm{~W} / \mathrm{cm}^{2}$ and $0.7 \mathrm{~K}$, respectively. Cross with a rightward arrow indicates critical heat flux and the subsequent temperature excursion. The horizontal dashed line indicates the critical heat flux predicted by Zuber's proposed hydrodynamic limit [35].

\section{Conclusions}

The set of experiments described herein has clarified the roles of different wettability characteristics on boiling behavior. The intrinsic wettability of the surface, as indicated by static contact angle measurements, plays a role in the nucleation behavior and heat transfer efficacy of a surface during boiling; however, the receding contact angle is the dominant factor governing the bubble growth dynamics and, ultimately, the critical heat flux on surfaces in the absence of capillary wicking. The hydrophobic surfaces with low receding contact angles evaluated in this study maintain the advantageous low-superheat boiling incipience and high active nucleation site densities commonly observed on hydrophobic surfaces, but prevent the vapor spreading during bubble growth that commonly plagues these surfaces when their receding contact angle is high. This results in decreased surface temperatures during nucleate boiling compared to hydrophilic surfaces and little to no detriment to critical heat flux. Texturing hydrophobic surfaces to minimize the receding contact angle provides a further avenue for boiling performance enhancement. The boiling behavior of parahydrophobic surfaces with rose-petal-like wettability is studied. Textured parahydrophobic 
surfaces with low receding contact angles are demonstrated to improve the boiling efficacy compared to smooth hydrophobic surfaces of the same material through further reduction in surface temperatures. The understanding obtained in this study ushers in a new class of surfaces with wide applicability for enhanced boiling: hydrophobic surfaces that have low receding contact angles.

\section{Acknowledgment}

This work was supported as part of Purdue's NEPTUNE Center for Power and Energy, funded by the Office of Naval Research under Award Number N000141613109.

The first author acknowledges support from the Department of Defense (DoD) National Defense Science and Engineering Graduate Fellowship (NDSEG) program, sponsored by the Air Force Office of Scientific Research (AFOSR). The authors thank the Wright Flower Shop in West Lafayette, IN for providing the rose petals. The authors thank Laurie Mueller of the Purdue University Life Sciences Microscopy Facility for preparing and imaging the rose petal.

\section{Appendix A. Supplementary Videos}

The Supplementary Videos associated with this article can be found in the online version at [insert url].

\section{Appendix B. Bubble Growth Model Derivation}

The bubble growth model considers a balance between the buoyancy force acting upward on the bubble

$$
F_{b}=\left(\rho_{l}-\rho_{v}\right) V g
$$

(where $\rho_{l}$ and $\rho_{g}$ are the densities of the liquid and vapor, $V$ the bubble volume, and $g$ the gravitational constant) and the surface tension force holding it to the surface

$$
F_{s}=\gamma\left(\pi D_{b}\right) \sin \theta
$$

(where $\gamma$ is the liquid-vapor surface tension, $D_{b}$ the base diameter of the bubble, and $\theta$ the contact angle). It is assumed that the bubble grows with the liquid at the receding contact angle as a spherical cap. The volume of a spherical cap can be calculated as follows (variables defined in Figure A1):

$$
V_{\text {cap }}=\frac{1}{3} \pi R^{3}\left(2-3 \sin \alpha+\sin ^{3} \alpha\right)
$$

The sphere radius, $R$, and the angle, $\alpha$, are substituted for the bubble base diameter, $D_{b}$, and the liquid receding contact angle, $\theta_{\text {rec }}$, which can be readily measured in the experiments. The sphere radius is related to the bubble base diameter as $\cos \alpha=D_{b} / 2 R$. The angle $\alpha$ can be related to the liquid receding contact angle as $\alpha=\theta_{\text {rec }}-\pi / 2$. Substituting these expressions into Eq. (A3): 


$$
V_{\text {cap }}=\frac{1}{24} \pi\left(\frac{D_{b}}{\sin \theta_{\text {rec }}}\right)^{3}\left(2+3 \cos \theta_{\text {rec }}-\cos ^{3} \theta_{\text {rec }}\right)
$$

Substituting Eq. (A4) into the relation for the buoyancy force (Eq. (A1)), and setting the buoyancy force equal to the surface tension force (i.e. the condition for bubble departure), the balance between buoyancy and surface tension forces is

$$
\frac{1}{24} g\left(\rho_{l}-\rho_{v}\right) \pi\left(\frac{D_{b}}{\sin \theta_{r e c}}\right)^{3}\left(2+3 \cos \theta_{r e c}-\cos ^{3} \theta_{r e c}\right)=\gamma_{l v} \pi D_{b} \sin \theta_{\text {rec }}
$$

Eq. (A5) can be simply solved to obtain an expression for the bubble base diameter immediately prior to departure:

$$
D_{b}=\sqrt{\frac{24 \gamma_{l v} \sin ^{4} \theta_{r e c}}{g\left(\rho_{l}-\rho_{v}\right)\left(2+3 \cos \theta_{r e c}-\cos ^{3} \theta_{r e c}\right)}}
$$

Once this base diameter and spherical cap volume are known, the bubble departure diameter can be obtained assuming the bubble departs as a sphere,

$$
D_{\text {depart }}=\sqrt[3]{6 V_{\text {cap }} / \pi}
$$

For surfaces with a receding contact angle of less than $90^{\circ}$, this model can be evaluated using the receding contact angle of the surface. As discussed in the manuscript, for surfaces with a high receding contact angle, the bubble is assumed to pinch off at some height above the surface with a contact angle perpendicular to the surface. Thus, volume and departure diameter are calculated assuming a receding contact angle of 90. The base diameter is then estimated according to Eq. (A4) using the calculated volume and the measured receding contact angle of the surface.

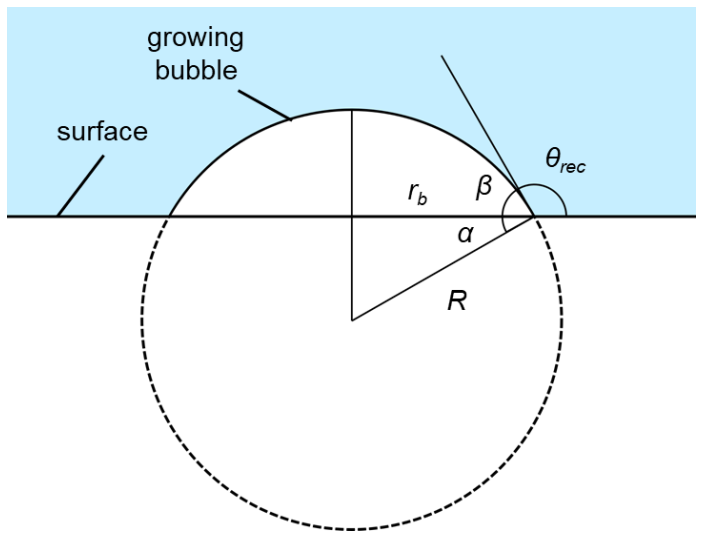

Figure A1. Schematic illustration of the geometry of a spherical cap bubble at the receding contact angle.

\section{References}


[1] S. Mori, Y. Utaka, Critical heat flux enhancement by surface modification in a saturated pool boiling: A review, Int. J. Heat Mass Transf. 108, Part B (2017) 2534-2557.

[2] G. Liang, I. Mudawar, Pool boiling critical heat flux (CHF) - Part 2: Assessment of models and correlations, Int. J. Heat Mass Transf. 117 (2018) 1368-1383.

[3] G. Liang, I. Mudawar, Pool boiling critical heat flux (CHF) - Part 1: Review of mechanisms, models, and correlations, Int. J. Heat Mass Transf. 117 (2018) 1352-1367.

[4] Y. Takata, S. Hidaka, M. Masuda, T. Ito, Pool boiling on a superhydrophilic surface, Int. J. Energy Res. 27 (2003) 111-119.

[5] Y. Takata, S. Hidaka, J.M. Cao, T. Nakamura, H. Yamamoto, M. Masuda, T. Ito, Effect of surface wettability on boiling and evaporation, Energy. 30 (2005) 209-220.

[6] H.S. Ahn, H.J. Jo, S.H. Kang, M.H. Kim, Effect of liquid spreading due to nano/microstructures on the critical heat flux during pool boiling, Appl. Phys. Lett. 98 (2011) 071908.

[7] B.S. Kim, H. Lee, S. Shin, G. Choi, H.H. Cho, Interfacial wicking dynamics and its impact on critical heat flux of boiling heat transfer, Appl. Phys. Lett. 105 (2014).

[8] M.M. Rahman, E. Ölçeroğlu, M. McCarthy, Role of wickability on the critical heat flux of structured superhydrophilic surfaces, Langmuir. 30 (2014) 11225-11234.

[9] N.S. Dhillon, J. Buongiorno, K.K. Varanasi, Critical heat flux maxima during boiling crisis on textured surfaces, Nat. Commun. 6 (2015) 8247.

[10] A.R. Girard, J. Kim, S.M. You, Pool boiling heat transfer of water on hydrophilic surfaces with different wettability, Proc. Of ASME International Mechanical Engineering Congress \& Exposition. 8 (2016).

[11] A.R. Betz, J. Xu, H. Qiu, D. Attinger, Do surfaces with mixed hydrophilic and hydrophobic areas enhance pool boiling?, Appl. Phys. Lett. 97 (2010) 141909.

[12] H. Jo, H.S. Ahn, S. Kang, M.H. Kim, A study of nucleate boiling heat transfer on hydrophilic, hydrophobic and heterogeneous wetting surfaces, Int. J. Heat Mass Transf. 54 (2011) 5643-5652.

[13] B. Bourdon, E. Bertrand, P. Di Marco, M. Marengo, R. Rioboo, J. De Coninck, Wettability influence on the onset temperature of pool boiling: Experimental evidence onto ultra-smooth surfaces, Adv. Colloid Interface Sci. 221 (2015) 34-40.

[14] V.P. Carey, Liquid Vapor Phase Change Phenomena: An Introduction to the Thermophysics of Vaporization and Condensation Processes in Heat Transfer Equipment, 2nd ed., Taylor \& Francis, 2008.

[15] M. Zupančič, M. Steinbücher, P. Gregorčič, I. Golobič, Enhanced pool-boiling heat transfer on lasermade hydrophobic/superhydrophilic polydimethylsiloxane-silica patterned surfaces, Appl. Therm. Eng. 91 (2015) 288-297. 
[16] S. Gong, P. Cheng, Lattice Boltzmann simulations for surface wettability effects in saturated pool boiling heat transfer, Int. J. Heat Mass Transf. 85 (2015) 635-646.

[17] B. Shen, M. Yamada, S. Hidaka, J. Liu, J. Shiomi, G. Amberg, M. Do-Quang, M. Kohno, K. Takahashi, Y. Takata, Early Onset of Nucleate Boiling on Gas-covered Biphilic Surfaces, Sci. Rep. 7 (2017) 2036.

[18] C. Frankiewicz, D. Attinger, On Temporal Biphilicity: Definition, Relevance, and Technical Implementation in Boiling Heat Transfer, J. Heat Transf. 139 (2017).

[19] Y. Lai, J. Huang, Z. Cui, M. Ge, K.-Q. Zhang, Z. Chen, L. Chi, Recent advances in TIO2-based nanostructured surfaces with controllable wettability and adhesion, Small. 12 (2016) 2203-2224.

[20] A.B.D. Cassie, S. Baxter, Wettability of porous surfaces, Trans. Faraday Soc. 40 (1944) 546-551.

[21] R.N. Wenzel, Surface roughness and contact angle., J. Phys. Colloid Chem. 53 (1949) 1466-1467.

[22] A. Lafuma, D. Quéré, Superhydrophobic states, Nat. Mater. 2 (2003) 457-460.

[23] B. He, J. Lee, N.A. Patankar, Contact angle hysteresis on rough hydrophobic surfaces, Colloids Surf. Physicochem. Eng. Asp. 248 (2004) 101-104.

[24] C. Dorrer, J. Rühe, Some thoughts on superhydrophobic wetting, Soft Matter. 5 (2008) 51-61.

[25] Y.Y. Yan, N. Gao, W. Barthlott, Mimicking natural superhydrophobic surfaces and grasping the wetting process: A review on recent progress in preparing superhydrophobic surfaces, Adv. Colloid Interface Sci. 169 (2011) 80-105.

[26] S. Dash, M.T. Alt, S.V. Garimella, Hybrid Surface Design for Robust Superhydrophobicity, Langmuir. 28 (2012) 9606-9615.

[27] N.A. Patankar, Transition between superhydrophobic states on rough surfaces, Langmuir. 20 (2004) 7097-7102.

[28] T. Koishi, K. Yasuoka, S. Fujikawa, T. Ebisuzaki, X.C. Zeng, Coexistence and transition between Cassie and Wenzel state on pillared hydrophobic surface, Proc. Natl. Acad. Sci. 106 (2009) 84358440 .

[29] Y. Takata, S. Hidaka, T. Uraguchi, Boiling Feature on a Super Water-Repellent Surface, Heat Transf. Eng. 27 (2006) 25-30.

[30] C.-C. Hsu, P.-H. Chen, Surface wettability effects on critical heat flux of boiling heat transfer using nanoparticle coatings, Int. J. Heat Mass Transf. 55 (2012) 3713-3719.

[31] I. Malavasi, B. Bourdon, P. Di Marco, J. de Coninck, M. Marengo, Appearance of a low superheat "quasi-Leidenfrost" regime for boiling on superhydrophobic surfaces, Int. Commun. Heat Mass Transf. 63 (2015) 1-7.

[32] Y. Li, K. Zhang, M.-C. Lu, C. Duan, Single bubble dynamics on superheated superhydrophobic surfaces, Int. J. Heat Mass Transf. 99 (2016) 521-531. 
[33] E. Teodori, T. Valente, I. Malavasi, A.S. Moita, M. Marengo, A.L.N. Moreira, Effect of extreme wetting scenarios on pool boiling conditions, Appl. Therm. Eng. 115 (2017) 1424-1437.

[34] T.P. Allred, J.A. Weibel, S.V. Garimella, Enabling highly effective boiling from superhydrophobic surfaces, Phys. Rev. Lett. 120 (2018) 174501.

[35] N. Zuber, Hydrodynamic aspects of boiling heat transfer, University of California, Los Angeles, 1959.

[36] L. Feng, Y. Zhang, J. Xi, Y. Zhu, N. Wang, F. Xia, L. Jiang, Petal effect: a superhydrophobic state with high adhesive force, Langmuir. 24 (2008) 4114-4119.

[37] H. Jin, Y. Li, P. Zhang, S. Nie, N. Gao, The investigation of the wetting behavior on the red rose petal, Appl. Phys. Lett. 108 (2016) 151605.

[38] S. Yang, J. Ju, Y. Qiu, Y. He, X. Wang, S. Dou, K. Liu, L. Jiang, Peanut leaf inspired multifunctional surfaces, Small. 10 (2014) 294-299.

[39] C.R. Szczepanski, F. Guittard, T. Darmanin, Recent advances in the study and design of parahydrophobic surfaces: From natural examples to synthetic approaches, Adv. Colloid Interface Sci. 241 (2017) 37-61.

[40] J. Wang, Q. Yang, M. Wang, C. Wang, L. Jiang, Rose petals with a novel and steady air bubble pinning effect in aqueous media, Soft Matter. 8 (2012) 2261-2266.

[41] Z.-G. Guo, W.-M. Liu, Sticky superhydrophobic surface, Appl. Phys. Lett. 90 (2007) 223111.

[42] J.Y. Park, D. Ahn, Y.Y. Choi, C.M. Hwang, S. Takayama, S.H. Lee, S.-H. Lee, Surface chemistry modification of PDMS elastomers with boiling water improves cellular adhesion, Sens. Actuators B Chem. 173 (2012) 765-771.

[43] K. Brown, H. Coleman, W. Steele, Estimating Uncertainty Intervals for Linear Regression, in: Proc. 33rd Aerosp. Sci. Meet. Exhib., Reno, NV, 1995.

[44] Y. Chen, R. Mertz, R. Kulenovic, Numerical simulation of bubble formation on orifice plates with a moving contact line, Int. J. Multiph. Flow. 35 (2009) 66-77.

[45] W. Barthlott, C. Neinhuis, Purity of the sacred lotus, or escape from contamination in biological surfaces, Planta. 202 (1997) 1-8. 


\section{List of Tables}

Table 1. Average contact angle measurements for each surface studied. 


\section{List of Figures}

Figure 1. Scanning electron microscope images of the aluminum textured surfaces fabricated in this study. (a) Chemically-etched parahydrophobic surface texture with large (tens of microns) relatively smooth structures separated by fissures. (b) Laser-etched superhydrophobic surface texture with stochastic roughness made up of fused spheroidal particles; structures range in size from ones to tens of microns. (c) Rose petal surface with micron-sized ridges on top of microscale bumps on the order of tens of microns. Figure 2. Schematic illustration of (a) pool boiling chamber and (b)-(c) test block. (b) top-down view of the thermocouple locations and the surface footprint area corresponding to each thermocouple rake; and (c) side-view of the thermocouple rakes with vertical dimensions.

Figure 3. Wettability characterization and boiling results for smooth hydrophilic and hydrophobic surfaces. Static $5 \mu \mathrm{L}$ droplets on (a) smooth copper, (b) smooth PDMS-coated, and (c) smooth Teflon-coated surfaces. Receding droplets on (d) smooth copper, (e) smooth PDMS-coated, and (f) smooth Teflon-coated surfaces. (g) Boiling curves (heat flux versus surface superheat) for each of the smooth surfaces. Calculated uncertainties in heat flux and surface superheat are less than $3 \mathrm{~W} / \mathrm{cm}^{2}$ and $0.7 \mathrm{~K}$, respectively. Crosses with a rightward arrow indicate critical heat flux and subsequent temperature excursions. The horizontal dashed line indicates the critical heat flux predicted by Zuber's proposed hydrodynamic limit [35].

Figure 4. Images comparing the boiling behavior on smooth surfaces. (a) Sparse nucleate boiling from the smooth copper surface (heat flux: $8.3 \mathrm{~W} / \mathrm{cm}^{2}$; superheat: $9.9 \mathrm{~K}$ ), (b) dense nucleate boiling from the smooth PDMS-coated surface $\left(7.5 \mathrm{~W} / \mathrm{cm}^{2} ; 7.9 \mathrm{~K}\right)$, and (c) film boiling from the smooth Teflon-coated surface $(6.7$ $\left.\mathrm{W} / \mathrm{cm}^{2} ; 36.7 \mathrm{~K}\right)$. For high-speed videos of the boiling behavior, refer to Appendix A.

Figure 5. Bubble growth dynamics and ebullition cycle. (a) Receding contact angle measurement of a droplet on the smooth PDMS-coated surface and (b) image showing a similarly small receding contact angle during bubble growth on the same surface. (c) Bubble ebullition cycle on a PDMS-coated surface exhibiting low-receding-angle growth. (d) Receding contact angle measurement of a droplet on the Tefloncoated surface and (e) image of a growing bubble on the same surface showing a similarly large receding contact angle. (f) Bubble ebullition cycle on a Teflon-coated surface exhibiting high-receding-angle growth. Scale bars, $3 \mathrm{~mm}$. Note the different length and time scales indicated on (c) and (f). For high-speed videos of the bubble dynamics, refer to Appendix A.

Figure 6. Illustration of approximate bubble growth progressions and results of bubble growth model. Bubble growth and departure on a surface with (a)-(c) low receding contact angle and (d)-(f) high receding contact angle. (g) Model results for the bubble departure diameter and maximum bubble base diameter plotted along with experimental results from the smooth surfaces.

Figure 7. Wettability characterization and boiling results for textured PDMS-coated surfaces. Static $5 \mu \mathrm{L}$ droplets on (a) parahydrophobic PDMS-coated surface (para PDMS), (b) superhydrophobic PDMS- 
coated surface (SHPho PDMS), and (c) rose petal. Receding droplets on (d) parahydrophobic PDMScoated surface, (e) superhydrophobic PDMS-coated surface, and (f) rose petal. (g) Boiling curves (heat flux versus surface superheat) for the textured PDMS-coated surfaces compared with the smooth copper and PDMS-coated surfaces. Calculated uncertainties in heat flux and superheat are less than $3 \mathrm{~W} / \mathrm{cm}^{2}$ and $0.7 \mathrm{~K}$, respectively. Crosses with a rightward arrow indicate critical heat flux and subsequent temperature excursions. The horizontal dashed line indicates the critical heat flux predicted by Zuber's proposed hydrodynamic limit [35].

Figure 8. Comparison of the bubble ebullition cycle and boiling behavior of the textured PDMS-coated surfaces. (a) Bubble ebullition cycle on the parahydrophobic PDMS-coated and (c) growth, coalescence and departure of first bubbles on the superhydrophobic PDMS-coated surface at incipience. Low-heat-flux boiling behavior of (b) the parahydrophobic PDMS-coated surface (heat flux: $7.8 \mathrm{~W} / \mathrm{cm}^{2}$; superheat: $5.8 \mathrm{~K}$ ) and (d) the superhydrophobic PDMS-coated surface $\left(7.3 \mathrm{~W} / \mathrm{cm}^{2} ; 12.5 \mathrm{~K}\right)$. Scale bars, $2 \mathrm{~mm}$. For high-speed videos of the bubble dynamics, refer to Appendix A.

Figure 9. Wetting behavior and boiling results for parahydrophobic PDMS-coated (para PDMS) and Teflon-coated (para Teflon) surfaces. A $5 \mu \mathrm{L}$ droplet adhered to (a) parahydrophobic PDMS-coated surface, (b) parahydrophobic Teflon-coated surface, and (c) rose petal while tilted at $90^{\circ}$. (d) Boiling curves (heat flux versus surface superheat) for the two parahydrophobic surfaces with insets showing the receding contact angle measurements for each surface. Calculated uncertainty for the heat flux and superheat are less than $3 \mathrm{~W} / \mathrm{cm}^{2}$ and $0.7 \mathrm{~K}$, respectively. Cross with a rightward arrow indicates critical heat flux and the subsequent temperature excursion. The horizontal dashed line indicates the critical heat flux predicted by Zuber's proposed hydrodynamic limit [35].

Figure A1. Schematic illustration of the geometry of a spherical cap bubble at the receding contact angle. 